\title{
Exercise-Induced Rhabdomyolysis and Stress-Induced Malignant Hyperthermia Events, Association with Malignant Hyperthermia Susceptibility, and RYR1 Gene Sequence Variations
}

\author{
Antonella Carsana ${ }^{1,2}$ \\ ${ }^{1}$ Department of Molecular Medicine and Medical Biotechnology, University of Naples Federico II, 80131 Naples, Italy \\ ${ }^{2}$ CEINGE-Biotecnologie Avanzate, 80145 Naples, Italy \\ Correspondence should be addressed to Antonella Carsana; carsana@unina.it
}

Received 29 November 2012; Accepted 16 January 2013

Academic Editors: L. Guimarães-Ferreira, H. Nicastro, J. Wilson, and N. E. Zanchi

Copyright (C) 2013 Antonella Carsana. This is an open access article distributed under the Creative Commons Attribution License, which permits unrestricted use, distribution, and reproduction in any medium, provided the original work is properly cited.

\begin{abstract}
Exertional rhabdomyolysis (ER) and stress-induced malignant hyperthermia $(\mathrm{MH})$ events are syndromes that primarily afflict military recruits in basic training and athletes. Events similar to those occurring in ER and in stress-induced MH events are triggered after exposure to anesthetic agents in $\mathrm{MH}$-susceptible (MHS) patients. $\mathrm{MH}$ is an autosomal dominant hypermetabolic condition that occurs in genetically predisposed subjects during general anesthesia, induced by commonly used volatile anesthetics and/or the neuromuscular blocking agent succinylcholine. Triggering agents cause an altered intracellular calcium regulation. Mutations in RYR1 gene have been found in about $70 \%$ of $\mathrm{MH}$ families. The RYR1 gene encodes the skeletal muscle calcium release channel of the sarcoplasmic reticulum, commonly known as ryanodine receptor type 1 (RYR1). The present work reviews the documented cases of ER or of stress-induced MH events in which RYR1 sequence variations, associated or possibly associated to MHS status, have been identified.
\end{abstract}

\section{Introduction}

Rhabdomyolysis is an acute syndrome determined by a direct or indirect muscle injury. It results from skeletal muscle breakdown and massive release of the intracellular content into blood circulation, which can lead to potentially fatal events, such as acute renal failure, hyperkalemia, and other metabolic complications $[1,2]$. The etiology of rhabdomyolysis is broad and includes inherited diseases, drugs, toxins, muscle compression, overexertion, and infections. Regardless of the mechanism, these muscle injuries ultimately lead to a leakage of $\mathrm{Ca}^{2+}$ ions into the intracellular space, and the excess of $\mathrm{Ca}^{2+}$ ions gives rise to a persistent muscle contraction that ends in energy depletion and cell death (Figure 1) [1]. Rhabdomyolysis syndrome may also occur as a result of a strenuous or not strenuous physical exercise (exertional rhabdomyolysis or ER) often in hot and humid climates. Although anyone may develop ER under extreme physical and environmental conditions, some individuals seem to be more predisposed than others, suggesting a genetic link. The most commonly identified predisposing conditions of ER are deficiencies of carnitine palmitoyltransferase II (CPT2 gene, OMIM *600650), myophosphorylase (McArdle disease, PYGM gene, OMIM *608455), and myoadenylate deaminase (AMPD1 gene, OMIM +102770). Events similar to those occurring in ER are triggered after exposure to anesthetic agents in malignant hyperthermia susceptible (MHS) patients. Therefore, an association between ER and malignant hyperthermia $(\mathrm{MH})$ has been investigated and reported [3-10]. However, two studies on the effect of exercise on thermoregulatory and metabolic responses in MHS subjects gave controversial results [11, 12]. Moreover, cases of $\mathrm{MH}-$ like events in the absence of anesthetic agents, and caused by high environmental or core body temperature, or even by emotional stress, have been reported [13-16].

Malignant hyperthermia (OMIM \#145600) is an autosomal dominant hypermetabolic condition that occurs in genetically predisposed subjects during general anesthesia, induced by commonly used volatile anesthetics and/or the neuromuscular blocking agent succinylcholine. Triggering agents cause an altered intracellular calcium regulation. An MH attack, unless immediately recognized and treated, is 


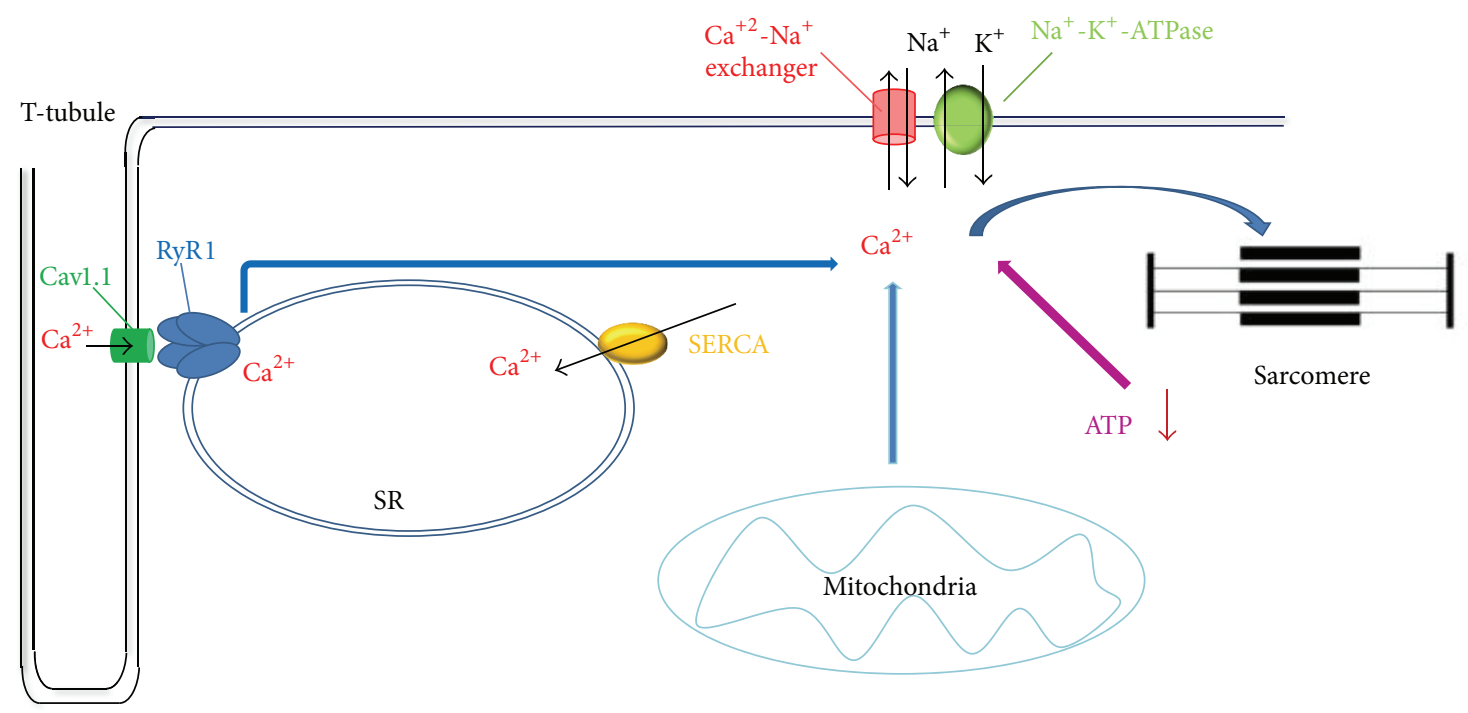

FIGURE 1: Schematic representation of a skeletal muscle cell and of $\mathrm{Ca}^{2+}$ and $\mathrm{Na}^{+}$ion fluxes across the sarcolemma and sarcoplasmic reticulum (SR). Activation of Cavl.1 by membrane depolarization causes the RyR1 channel to open and to release $\mathrm{Ca}^{2+}$ from SR, thus triggering muscle contraction. $\mathrm{Ca}^{2+}$ concentration is regulated by the $\mathrm{Ca}^{2+}$-ATPase membrane pump (SERCA) that sequesters $\mathrm{Ca}^{2+}$ in the $\mathrm{SR}$ and by the $\mathrm{Na}^{+}-$ $\mathrm{K}^{+}$-ATPase membrane pump and the $\mathrm{Ca}^{2+}-\mathrm{Na}^{+}$antiport that exchange $\mathrm{Ca}^{2+}$ for $\mathrm{Na}^{+}$across the sarcolemma. Regulation of calcium flux may be disrupted at any of these sites. ATP depletion, by consumption during muscle contraction, or reduced ATP production, results in intracellular $\mathrm{Ca}^{2+}$ increasing, muscle contraction, and continued energy consumption, leading to rhabdomyolysis.

often fatal. Clinical symptoms of a classic MH attack are accelerated muscle metabolism, muscle contractions, metabolic acidosis, tachycardia, and hyperthermia. These symptoms are correlated with some altered biochemical parameters, such as metabolic acidosis with increased $\mathrm{pCO}_{2}$ and lactate production and release of potassium and muscle proteins, as creatine kinase and myoglobin, into the blood. Frequent late events are damage of kidney function due to massive myoglobin release and/or a diffuse intravascular coagulation, which is often the main cause of death [17]. The prevalence of $\mathrm{MH}$ episodes is estimated to range from $1: 10,000$ to $1: 220,000$ [17]. Malignant hyperthermia susceptibility can be diagnosed by an in vitro test, based on the differential contractile response of normal (MHN) and MHS muscles to caffeine and halothane. Protocols for $\mathrm{MH}$ contracture testing of human skeletal muscle have been developed by the European [18] and North American [19] MH Groups, namely, in vitro contracture test (IVCT) and caffeine halothane contracture test (CHCT), respectively. A considerable genetic heterogeneity has been reported for MH. Six genetic loci (MHS1, OMIM \#180901; MHS2, OMIM \#154275; MHS3, OMIM \#154276; MHS4, OMIM \#600467; MHS5, OMIM \#601887; MHS6, OMIM \#601888-6), associated with $\mathrm{MH}$, have been identified. About $70 \%$ of affected families are linked to the MHS1 locus, where the RYR1 gene encoding the skeletal muscle calcium release channel of the sarcoplasmic reticulum, commonly known as ryanodine receptor type 1 (RyR1), maps. Dantrolene is an RyR1 antagonist that blocks calcium release from the sarcoplasmic reticulum stores and is the only specific agent available for the treatment of an $\mathrm{MH}$ attack. Less than $1 \%$ of MHS cases can be attributed to mutations in the CACNA1S gene (locus MHS5) encoding the $\alpha 1 S$ subunit of the voltagedependent L-type calcium channel of the skeletal muscle,
Cav1.1. Only three $\mathrm{MH}$-causing mutations identified in the CACNA1S gene were hitherto functionally characterized [2022]. RyR1 and Cavl.1 are the two major proteins involved in the excitation-contraction coupling in skeletal muscle.

The aim of this paper is to review the documented cases of ER or of stress-induced $\mathrm{MH}$ events in which sequence variations (SVs) of the RYR1 gene, associated or possibly associated to MHS, have been identified.

\section{Methods}

The PubMed and Web of Science databases were consulted to search for studies on documented cases of ER or of stressinduced $\mathrm{MH}$ events in which RYR1 SVs, associated or possibly associated to MHS, have been identified. Search terms included "RYR1," "mutation," "malignant hyperthermia," "exercise," "heat stress," "stress-induced malignant hyperthermia," and "nonanesthetic malignant hyperthermia." Singlenucleotide polymorphism (SNP) databases (http://www.ncbi .nlm.nih.gov/snp, http://www.dmd.nl/nmdb2/variants.php? select_db=RYR1) were also searched. Three different programs, namely, PMut (http://mmb.pcb.ub.es/PMut/), SIFT (http://sift.jcvi.org/), and PolyPhen-2 (http://genetics.bwh .harvard.edu/pph2/), were used to predict the pathological character of RYR1 SVs which have not been functionally characterized. PMut is based on the use of neural networks trained with a very large database of human diseaseassociated mutations and neutral SVs [23] and combines sequence alignment/position-specific scoring matrix with structural factors; score $>0.5$ predicts a pathological effect. SIFT is based on the degree of conservation of amino acid residues in sequence alignments derived from closely related sequences [24]. The SIFT scores range from 0 to 1 ; the amino 
acid substitution is predicted as damaging if the score is $\leq 0.05$ and as tolerated if the score is $>0.05$. PolyPhen- 2 predicts the effects of an amino acid substitution using both structure and sequence information [25] and classifies variants as "probably damaging," "possibly damaging," or "benign," based on pairs of false positive rate thresholds.

\section{Results}

3.1. RYR1 Gene Sequence Variations (SVs) in ER and StressInduced MH Patients. Thus far, more than 300 missense SVs have been identified in the RYR1 gene (http://www.ncbi.nlm .nih.gov/snp, http://www.dmd.nl/nmdb2/variants.php?select_ $\mathrm{db}=\mathrm{RYR})$. Some RYR1 SVs have been characterized by in vitro functional studies. The demonstration that a SV alters the kinetic properties of the RyR1 channel allows to define its role in the pathogenesis of MHS. Various methods have been developed to characterize the function of RyR1 variants: analysis of calcium release in human primary myotubes [2628] and in immortalized B lymphocytes from patients or after expression by transfection in various cell types [2931], determination of the channel openings in a ryanodine binding assay [32], and a metabolic test in vitro based on the measurements of proton release rate in immortalized B lymphocytes from patients [33]. MHS-associated RYR1 mutations cause the channels to become hypersensitive to activation by electrical and pharmacolog-i-cal (caffeine, halothane, 4chloro-m-cresol) stimuli. Identification of causative RYR1 mutations is an aid to the diagnosis of MHS. In fact, although the IVCT/CHCT are the gold standard to establish the risk of MHS, an individual harboring an $\mathrm{MH}$ causative mutation can be considered MHS even without an IVCT/CHCT result (http://www.emhg.org). Furthermore, genetic analysis is crucial to identify and evaluate the few cases of discordance between genotype, characterized by the presence of a causative mutation, and MHN-typed phenotype [34, 35]. A retrospective study reported these discordant cases in approximately $2.6 \%$ of $R Y R 1$ mutation-positive families [35]. Such discordant subjects are regarded as MHS for clinical purposes on the basis of genetic data alone, since they bear a causative mutation $[34,35]$.

Table 1 shows a list of RYR1 gene missense SVs and the corresponding amino acid substitutions, identified in patients who experienced ER or stress-induced $\mathrm{MH}$ events [10, 13-16, 36-38]. Four RYR1 SVs, corresponding to the amino acid substitutions p.R163C, p.G341R, p.G2434R, and p.T4826I, have already been demonstrated to be causative of MHS (http://www.emhg.org). The p.R3983C substitution was identified in two unrelated children who had fatal, nonanesthetic awake episodes associated with febrile illness and heat stress [15]. One of the children also had the variant p.D $4505 \mathrm{H}$. Interestingly, the child who only had the p.R3983 variant also had an $\mathrm{MH}$ attack during general anesthesia with halothane. These two SVs were functionally characterized by evaluating the caffeine sensitivity of $\mathrm{Ca}^{2+}$ release in transfected myotubes. Both p.R3983C and p.D4505H RyR1 channel variants exhibit an increase in the sensitivity to activation by caffeine, although the effect of the p.R3983C substitution alone is quite modest [15]. The SVs
p.R401C, p.A933T, p.G2160S, p.R2336H, p.T4288_A4290dup, p.T4294 M, p.L4320_R4322dup, and p.R4645Q were reported to be absent in at least 100 control chromosomes. Instead, the p.S1342G and the p.S1352G variants are present among the African American population with a frequency of $4 \%$ and $2.7 \%$, respectively [39], indicating that they are neutral polymorphic changes in RyR1. The p.R2336H, p.T4288_A4290dup, p.L4320_R4322dup, and p.R4645Q SVs have already been reported in MHS families [40-42].

3.2. In Silico Analysis of RYR1 Variants Reported in Patients Who Experienced ER and Stress-Induced MH Events. To predict the pathological character of p.E209 K, p.R401C, p.A933T, p.G2160S, p.R2336H, p.T4294 M, and p.R4645Q SVs, I tested them with 3 different prediction programs, namely, PMut (http://mmb.pcb.ub.es/PMut/) [23], SIFT (http://sift.jcvi.org/) [24], and PolyPhen-2 (http://genetics .bwh.harvard.edu/pph2/) [25]. Table 2 shows the results obtained by this analysis. The p.R401C, p.A933T, and p.R2336H variants were predicted to have a pathological character, while the predictions generated for p.E209 K, p.G2160S, p.T4294 M, and p.R4645Q variants were divergent. The p.E209 K variant, that has been predicted to be neutral by two programs and only possibly damaging by PolyPhen-2, has been found in association with p.R2336 in one patients who experienced stress-induced $\mathrm{MH}$ events and was typed MHS by CHCT (see Table 1) [36]. All the programs tested predict a pathological effect for the p.R2336 $\mathrm{H}$ variant, that could be the molecular basis of both phenotypes. However, functional studies are needed to conclusively define the exact pathogenic effects of this amino acid substitution and to assess if it is the cause of stress-induced $\mathrm{MH}$ events in the patient.

Wappler et al. [10] found causative mutations (p.R163C, p.G341R, and p.G2434R) in only three out of ten MHS patients who experienced ER. They screened only eight $R Y R 1$ exons located in the hotspot region; therefore, this limited analysis can explain the low mutation detection rate. Moreover, Sambuughin et al. [39], by sequencing the RYR1 cDNA, found putative causative SVs (p.A933T and p.T4294 M) in only two out of six ER/MHS patients studied. In the remaining cases, the ER/MHS phenotype could be caused by RYR1 SVs which may escape the RYR1 cDNA screening because they determine unbalanced allelic expression [43-46] or, alternatively, could be caused by mutations in other candidate MHS loci genes.

\section{Conclusions and Perspectives}

$\mathrm{ER}$ and stress-induced $\mathrm{MH}$ events are syndromes with diverse etiologies that afflict particularly military recruits in basic training and athletes. This paper reports an overview of the literature on cases associated with MHS and with RYR1 causative mutations or putative causative SVs. The possible disease-causing role of SVs, identified in patients who experienced ER and stress-induced $\mathrm{MH}$ events and that have not been functionally characterized, was investigated by computational analysis by using three different approaches, to increase the predictive power. Although only the molecular 
TABLE 1: RYR1 sequence variants reported in patients who experienced ER and stress-induced MH events.

\begin{tabular}{|c|c|c|c|c|c|c|c|c|}
\hline Nucleotide change & Exons & $\begin{array}{l}\text { Aminoacid } \\
\text { change }\end{array}$ & $\begin{array}{c}\text { MH-causative } \\
\text { mutation } \\
\text { (http://www.emhg.org) }\end{array}$ & $\begin{array}{l}\text { Unrelated } \\
\text { patients } \\
(n)\end{array}$ & $\begin{array}{l}\text { Regions of the } \\
R Y R 1 \text { gene } \\
\text { investigated }\end{array}$ & $\mathrm{dbSNP}$ & $\begin{array}{c}\text { MH } \\
\text { status }\end{array}$ & References \\
\hline c. $487 \mathrm{C}>\mathrm{T}$ & 6 & $\mathrm{R} 163 \mathrm{C}$ & Yes & $\begin{array}{l}1 \\
1\end{array}$ & gDNA hot spot & rs118192161 & $\begin{array}{l}\text { MHS } \\
\text { n.d }\end{array}$ & $\begin{array}{l}{[10]} \\
{[13]}\end{array}$ \\
\hline $\begin{array}{l}\text { c. } 625 \mathrm{G}>\mathrm{A} \\
\text { c. } 7007 \mathrm{G}>\mathrm{A}\end{array}$ & $\begin{array}{c}7 \\
43\end{array}$ & $\begin{array}{l}\mathrm{E} 209 \mathrm{~K} / \\
\mathrm{R} 2336 \mathrm{H}\end{array}$ & & 1 & $\begin{array}{c}\text { cDNA } \\
\text { complete }\end{array}$ & $\frac{-}{\mathrm{rs} 112563513}$ & MHS & {$[36]$} \\
\hline c. $1021 \mathrm{G}>\mathrm{A}$ & 11 & G341R & Yes & 1 & gDNA hot spot & rs121918592 & MHS & {$[10]$} \\
\hline c. $1201 \mathrm{C}>\mathrm{T}$ & 12 & $\mathrm{R} 401 \mathrm{C}$ & & 2 & cDNA hot spot & - & MHS & {$[16]$} \\
\hline $\begin{array}{l}\text { c. } 2797 \mathrm{G}>\mathrm{A} \\
\text { c. } 4024 \mathrm{~A}>\mathrm{G} \\
\text { c. } 4055 \mathrm{C}>\mathrm{G}\end{array}$ & $\begin{array}{l}23 \\
28 \\
28\end{array}$ & $\begin{array}{l}\text { A933T/ } \\
\text { S1342G/ } \\
\text { A1352G }\end{array}$ & & 1 & $\begin{array}{l}\text { cDNA } \\
\text { complete }\end{array}$ & $\begin{array}{c}\text { rs148623597 } \\
\text { rs34694816 } \\
\text { rs112105381 }\end{array}$ & MHS & {$[39]$} \\
\hline c. $4024 \mathrm{~A}>\mathrm{G}$ & 28 & $\mathrm{~S} 1342 \mathrm{G}$ & & 3 & $\begin{array}{c}\text { cDNA } \\
\text { complete }\end{array}$ & rs34694816 & MHS & {$[37,39]$} \\
\hline $\begin{array}{l}\text { c. } 4024 \mathrm{~A}>\mathrm{G} \\
\text { c. } 4055 \mathrm{C}>\mathrm{G} \\
\text { c. } 12861 \_12869 \mathrm{dup} \\
\text { c. } 12881 \mathrm{C}>\mathrm{T}\end{array}$ & $\begin{array}{l}28 \\
28 \\
91 \\
91\end{array}$ & $\begin{array}{c}\text { S1342G/ } \\
\text { A1352G/ } \\
\text { T4288_A4290dup/ } \\
\text { T4294M }\end{array}$ & & 1 & $\begin{array}{l}\text { cDNA } \\
\text { complete }\end{array}$ & $\begin{array}{c}\text { rs34694816 } \\
\text { rs112105381 } \\
- \\
-\end{array}$ & MHS & {$[39]$} \\
\hline $\begin{array}{l}\text { c. } 2797 \mathrm{G}>\mathrm{A} \\
\text { c. } 6478 \mathrm{G}>\mathrm{A}\end{array}$ & $\begin{array}{l}28 \\
39\end{array}$ & $\begin{array}{l}\text { S1342G/ } \\
\text { G2160S }\end{array}$ & & 1 & $\begin{array}{c}\text { cDNA } \\
\text { complete }\end{array}$ & $\begin{array}{l}\text { rs34694816 } \\
\text { rs143398211 }\end{array}$ & MHS & [39] \\
\hline c.7300G $>A$ & 45 & G2434R & Yes & 1 & $\begin{array}{l}\text { gDNA } \\
\text { hot spot }\end{array}$ & rs121918593 & MHS & {$[10]$} \\
\hline c. $11947 \mathrm{C}>\mathrm{T}$ & 87 & R3983C & Yes & $1^{*}$ & $\begin{array}{l}\text { gDNA (106 } \\
\text { exons) }\end{array}$ & - & n.d. & {$[15]$} \\
\hline $\begin{array}{l}\text { c. } 11947 \mathrm{C}>\mathrm{T} \\
\text { c. } 13513 \mathrm{G}>\mathrm{C}\end{array}$ & $\begin{array}{l}87 \\
92\end{array}$ & $\begin{array}{l}\mathrm{R} 3983 \mathrm{C} / \\
\mathrm{D} 4505 \mathrm{H}\end{array}$ & $\begin{array}{l}\text { Yes } \\
\text { Yes }\end{array}$ & $1^{*}$ & $\begin{array}{l}\text { gDNA (106 } \\
\text { exons) }\end{array}$ & - & MHS & {$[15]$} \\
\hline $\begin{array}{l}\text { c.12959_12967dup } \\
\text { c.13934G>A }\end{array}$ & $\begin{array}{l}91 \\
95\end{array}$ & $\begin{array}{c}\text { L4320_R4322dup/ } \\
\text { R4645Q }\end{array}$ & & $1^{*}$ & $\begin{array}{l}\text { gDNA (106 } \\
\text { exons) }\end{array}$ & - & n.d. & {$[14]$} \\
\hline c. $14473 \mathrm{C}>\mathrm{T}$ & 100 & T4826I & Yes & $1^{*}$ & $\begin{array}{c}\text { cDNA } \\
\text { complete }\end{array}$ & rs121918595 & n.d. & {$[38]$} \\
\hline
\end{tabular}

* patients who experienced stress-induced MH events; n.d.: not determined. Nucleotide substitutions were numbered on the cDNA sequence (GenBank NM_000540.2); gDNA: genomic DNA.

TABLE 2: In silico analysis of RYR1 sequence variants reported in patients who experienced ER and stress-induced MH events.

\begin{tabular}{lccc}
\hline Sequence variant & PMut & SIFT & Polyphen-2 \\
\hline p.E209K & $\mathbf{0 . 6 5 9 8}$ & 0.29 & Possibly damaging \\
p.R401C & $\mathbf{0 . 8 4 0 0}$ & $\mathbf{0 . 0 4}$ & Probably damaging \\
p.A933T & $\mathbf{0 . 5 9 6 9}$ & $\mathbf{0 . 0 1}$ & Probably damaging \\
p.G2160S & 0.2159 & 0.49 & Possibly damaging \\
p.R2336H & $\mathbf{0 . 8 3 7 7}$ & $\mathbf{0 . 0 0}$ & Probably damaging \\
p.T4294M & $\mathbf{0 . 8 9 9 4}$ & 0.11 & Benign \\
p.R4645Q & $\mathbf{0 . 8 2 6 1}$ & $\mathbf{0 . 0 0}$ & Benign \\
\hline
\end{tabular}

Scores predicting pathological effect are in bold: PMut, $>0.5$; SIFT $\leq 0.05$. Polyphen-2 classifies the sequence variants as probably damaging, possibly damaging, or benign.

characterization of RyR1 channel variants can define the functional impact of a given SV, in silico predictions, which are fast and relatively inexpensive methods, may filter out SVs that are unlikely to affect protein function and allow phenotype prediction based on the biochemical severity of the amino acid substitution and on the protein sequence and structural information. Overall, the data presented in this paper emphasize the concept that some RYR1 SVs are associated with both phenotypes and underline the importance of performing contracture testing and $R Y R 1$ variant screening in these patients.

A mouse model of heat- and anesthetic-induced MHS has been created by introducing the p.Y522S mutation in the RYR1 gene [47]. Only mice which are heterozygous for the p.Y522S mutation (RyR1 ${ }^{\mathrm{Y} 522 \mathrm{~S} / \mathrm{wt}}$ ) are viable and exhibit whole body contractions and elevated core temperatures in response to anesthetic exposure or heat stress [47]. Elevated environmental temperatures induce muscle contractures, rhabdomyolysis, and death in these mice. The $\mathrm{Ca}^{2+}$ leaking caused by the p.Y522S mutation, combined with temperature, generates increases in reactive nitrogen species and S-nitrosylation of the mutant channel that enhances RyRl channel activity. Ultimately, the exposure to elevated temperatures produces abnormal muscle contractures in the RyR1 ${ }^{\mathrm{Y} 522 \mathrm{~S} / \mathrm{wt}}$ mice [48]. Recently, it has been reported that AICAR, an activator of the AMP-activated protein kinase (AMPK), prevents $\mathrm{Ca}^{2+}$ leaking, generation of reactive oxygen and nitrogen species, and heat-induced sudden death in RyR1 ${ }^{\mathrm{Y} 522 \mathrm{~S} / \mathrm{wt}}$ mice [49]. The effect of AICAR is not due to an increase in AMPK 
activity but to the inhibition of RyR1 channel activity. On the basis of these results, Lanner et al. [49] proposed "the potential use of AICAR for prophylactic treatment in humans with enhanced susceptibility to exercise and/or heat-induced sudden death associated with RyR1 disease mutations." Moreover, studies on the effects of prior eccentric exercise on isolated mouse RyR $1^{\mathrm{Y} 522 \mathrm{~S} / \mathrm{wt}}$ muscle indicated that high-force eccentric contractions, run under nonthermally stressful conditions, may attenuate the thermal stress-induced loss of function [50]. This finding can have important implications because it suggests that the exercise-induced muscle injury may mitigate the severity of stress-induced $\mathrm{MH}$ episodes, possibly in humans as well.

\section{Acknowledgment}

This work was supported by Grants from Regione Campania (Protocollo d'Intesa CEINGE-Regione Campania, DGRC 1901/2009).

\section{References}

[1] R. Vanholder, M. S. Sever, E. Erek, and N. Lameire, "Rhabdomyolysis," Journal of the American Society of Nephrology, vol. 11, no. 8, pp. 1553-1561, 2000.

[2] J. D. Warren, P. C. Blumbergs, and P. D. Thompson, "Rhabdomyolysis: a review," Muscle \& Nerve, vol. 25, no. 3, pp. 332347,2002

[3] W. Hackl, M. Winkler, W. Mauritz, P. Sporn, and K. Steinbereithner, "Muscle biopsy for diagnosis of malignant hyperthermia susceptibility in two patients with severe exercise-induced myolysis," British Journal of Anaesthesia, vol. 66, no. 1, pp. 138140, 1991.

[4] P. J. E. Poels, E. M. G. Joosten, R. C. A. Sengers, A. M. Stadhouders, J. H. Veerkamp, and A. A. G. M. Benders, "In vitro contraction test for malignant hyperthermia in patients with unexplained recurrent rhabdomyolysis," Journal of the Neurological Sciences, vol. 105, no. 1, pp. 67-72, 1991.

[5] D. Figarella-Branger, G. Kozak-Ribbens, L. Rodet et al., "Pathological findings in 165 patients explored for malignant hyperthermia susceptibility," Neuromuscular Disorders, vol. 3, no. 5-6, pp. 553-556, 1993.

[6] J. W. Ogletree, J. F. Antognini, and G. A. Gronert, "Postexercise muscle cramping associated with positive malignant hyperthermia contracture testing," American Journal of Sports Medicine, vol. 24, no. 1, pp. 49-51, 1996.

[7] J. F. Ryan and L. G. Tedeschi, "Sudden unexplained death in a patient with a family history of malignant hyperthermia," Journal of Clinical Anesthesia, vol. 9, no. 1, pp. 66-68, 1997.

[8] M. R. Weglinski, D. J. Wedel, and A. G. Engel, "Malignant hyperthermia testing in patients with persistently increased serum creatine kinase levels," Anesthesia and Analgesia, vol. 84, no. 5, pp. 1038-1041, 1997.

[9] A. Köchling, F. Wappler, G. Winkler, and J. S. A. Esch, "Rhabdomyolysis following severe physical exercise in a patient with predisposition to malignant hyperthermia," Anaesthesia and Intensive Care, vol. 26, no. 3, pp. 315-318, 1998.

[10] F. Wappler, M. Fiege, M. Steinfath et al., "Evidence for susceptibility to malignant hyperthermia in patients with exerciseinduced rhabdomyolysis," Anesthesiology, vol. 94, no. 1, pp. 95100,2001
[11] I. T. Campbell, F. R. Ellis, R. T. Evans, and M. G. Mortimer, "Studies of body temperature, blood lactate, cortisol and free fatty acid levels during exercise in human subjects susceptible to malignant hyperpyrexia," Acta Anaesthesiologica Scandinavica, vol. 27, no. 5, pp. 349-355, 1983.

[12] J. H. Green, F. R. Ellis, and P. J. Halsall, "Thermoregulation, plasma catecholamine and metabolite levels during submaximal work in individuals susceptible to malignant hyperpyrexia," Acta Anaesthesiologica Scandinavica, vol. 31, no. 2, pp. 122-126, 1987.

[13] J. R. Tobin, D. R. Jason, V. R. Challa, T. E. Nelson, and N. Sambuughin, "Malignant hyperthermia and apparent heat stroke," Journal of the American Medical Association, vol. 286, no. 2, pp. 168-169, 2001.

[14] H. Nishio, T. Sato, S. Fukunishi et al., "Identification of malignant hyperthermia-susceptible ryanodine receptor type 1 gene (RYR1) mutations in a child who died in a car after exposure to a high environmental temperature," Legal Medicine, vol. 11, no. 3, pp. 142-143, 2009.

[15] L. Groom, S. M. Muldoon, Z. Z. Tang et al., "Identical de novo mutation in the RYR1 gene associated with fatal, stressinduced malignant hyperthermia in two unrelated families," Anesthesiology, vol. 115, no. 5, pp. 938-945, 2011.

[16] M. Davis, R. Brown, A. Dickson et al., "Malignant hyperthermia associated with exercise-induced rhabdomyolysis or congenital abnormalities and a novel RYR1 mutation in New Zealand and Australian pedigrees," British Journal of Anaesthesia, vol. 88, no. 4, pp. 508-515, 2002.

[17] O. Bandschapp and T. Girard, "Malignant hyperthermia," Swiss Medical Weekly, vol. 142, article w13652, 2012.

[18] F. R. Ellis, P. J. Halsall, and H. Ording, "A protocol for the investigation of malignant hyperpyrexia (MH) susceptibility," British Journal of Anaesthesia, vol. 56, no. 11, pp. 1267-1269, 1984.

[19] M. G. Larach, "Standardization of the caffeine halothane muscle contracture test. North American Malignant Hyperthermia Group," Anesthesia \& Analgesia, vol. 69, no. 4, pp. 511-515, 1989.

[20] R. G. Weiss, K. M. S. O'Connell, B. E. Flucher, P. D. Allen, M. Grabner, and R. T. Dirksen, "Functional analysis of the $\mathrm{R} 1086 \mathrm{H}$ malignant hyperthermia mutation in the DHPR reveals an unexpected influence of the III-IV loop on skeletal muscle EC coupling," American Journal of Physiology - Cell Physiology, vol. 287, no. 4, pp. C1094-C1102, 2004.

[21] A. Pirone, J. Schredelseker, P. Tuluc et al., "Identification and functional characterization of malignant hyperthermia mutation T1354S in the outer pore of the $\mathrm{Ca}_{\mathrm{v}} \alpha 1 \mathrm{~S}$ - subunit," American Journal of Physiology, vol. 299, no. 6, pp. C1345-C1354, 2010.

[22] J. M. Eltit, R. A. Bannister, O. Mouad et al., "Malignant hyperthermia susceptibility arising from altered resting coupling between the skeletal muscle L-type $\mathrm{Ca}^{2+}$ channel and the type 1 ryanodine receptor," Proceedings of the National Academy of Sciences, vol. 109, no. 20, pp. 7923-7928, 2012.

[23] C. Ferrer-Costa, J. L. Gelpí, L. Zamakola, I. Parraga, X. de la Cruz, and M. Orozco, "PMUT: a web-based tool for the annotation of pathological mutations on proteins," Bioinformatics, vol. 21, no. 14, pp. 3176-3178, 2005.

[24] P. C. Ng and S. Henikoff, "SIFT: predicting amino acid changes that affect protein function," Nucleic Acids Research, vol. 31, no. 13, pp. 3812-3814, 2003.

[25] V. Ramensky, P. Bork, and S. Sunyaev, "Human nonsynonymous SNPs: server and survey," Nucleic Acids Research, vol. 30, no. 17, pp. 3894-3900, 2002. 
[26] M. Wehner, H. Rueffert, F. Koenig, J. Neuhaus, and D. Olthoff, "Increased sensitivity to 4-chloro-m-cresol and caffeine in primary myotubes from malignant hyperthermia susceptible individuals carrying the ryanodine receptor 1 Thr2206Met (C6617T) mutation," Clinical Genetics, vol. 62, no. 2, pp. 135146, 2002.

[27] T. Girard, S. Treves, K. Censier, C. R. Mueller, F. Zorzato, and A. Urwyler, "Phenotyping malignant hyperthermia susceptibility by measuring halothane-induced changes in myoplasmic calcium concentration in cultured human skeletal muscle cells," British Journal of Anaesthesia, vol. 89, no. 4, pp. 571-579, 2002.

[28] H. Brinkmeier, J. Krämer, R. Krämer et al., "Malignant hyperthermia causing Gly2435Arg mutation of the ryanodine receptor facilitates ryanodine-induced calcium release in myotubes," British Journal of Anaesthesia, vol. 83, no. 6, pp. 855-861, 1999.

[29] T. Yang, T. A. Ta, I. N. Pessah, and P. D. Allen, "Functional defects in six ryanodine receptor isoform-1 (RYR1) mutations associated with malignant hyperthermia and their impact on skeletal excitation-contraction coupling," Journal of Biological Chemistry, vol. 278, no. 28, pp. 25722-25730, 2003.

[30] T. Girard, D. Cavagna, E. Padovan et al., "B-lymphocytes from malignant hyperthermia-susceptible patients have an increased sensitivity to skeletal muscle ryanodine receptor activators," Journal of Biological Chemistry, vol. 276, no. 51, pp. 4807748082, 2001.

[31] J. Tong, H. Oyamada, N. Demaurex, S. Grinstein, T. V. McCarthy, and D. H. MacLennan, "Caffeine and halothane sensitivity of intracellular $\mathrm{Ca}^{2+}$ release is altered by 15 calcium release channel (ryanodine receptor) mutations associated with malignant hyperthermia and/or central core disease," Journal of Biological Chemistry, vol. 272, no. 42, pp. 26332-26339, 1997.

[32] N. Sambuughin, T. E. Nelson, J. Jankovic et al., "Identification and functional characterization of a novel ryanodine receptor mutation causing malignant hyperthermia in North American and South American families," Neuromuscular Disorders, vol. 11, no. 6-7, pp. 530-537, 2001.

[33] A. Zullo, W. Klingler, C. De Sarno et al., "Functional characterization of ryanodine receptor (RYR1) sequence variants using a metabolic assay in immortalized B-lymphocytes," Human Mutation, vol. 30, no. 4, pp. E575-E590, 2009.

[34] G. Fortunato, A. Carsana, N. Tinto, V. Brancadoro, G. Canfora, and F. Salvatore, "A case of discordance between genotype and phenotype in a malignant hyperthermia family," European Journal of Human Genetics, vol. 7, no. 4, pp. 415-420, 1999.

[35] R. L. Robinson, M. J. Anetseder, V. Brancadoro et al., "Recent advances in the diagnosis of malignant hyperthermia susceptability: how confident can we be of genetic testing?" European Journal of Human Genetics, vol. 11, no. 4, pp. 342-348, 2003.

[36] J. Loke, N. Kraeva, and D. MacLennan, "Mutations in RYR1 gene associated with malignant hyperthermia and a nonanaesthetic phenotype," Canadian Journal of Anaesthesia, vol. 54, Supplement 1, p. 4609, 2007.

[37] J. F. Capacchione, N. Sambuughin, S. Bina, L. P. Mulligan, T. D. Lawson, and S. M. Muldoon, "Exertional rhabdomyolysis and malignant hyperthermia in a patient with ryanodine receptor type 1 gene, L-type calcium channel $\alpha$-1 subunit gene, and calsequestrin-1 gene polymorphisms," Anesthesiology, vol. 112, no. 1, pp. 239-244, 2010.

[38] R. L. Brown, A. N. Pollock, K. G. Couchman et al., "A novel ryanodine receptor mutation and genotype-phenotype correlation in a large malignant hyperthermia New Zealand
Maori pedigree," Human Molecular Genetics, vol. 9, no. 10, pp. 1515-1524, 2000.

[39] N. Sambuughin, J. Capacchione, A. Blokhin, M. Bayarsaikhan, S. Bina, and S. Muldoon, "The ryanodine receptor type 1 gene variants in African American men with exertional rhabdomyolysis and malignant hyperthermia susceptibility," Clinical Genetics, vol. 76, no. 6, pp. 564-568, 2009.

[40] S. Levano, M. Vukcevic, M. Singer et al., "Increasing the number of diagnostic mutations in malignant hyperthermia," Human Mutation, vol. 30, no. 4, pp. 590-598, 2009.

[41] D. Carpenter, R. L. Robinson, R. J. Quinnel et al., "Genetic variation in RYR1 and malignant hyperthermia phenotypes," British Journal of Anaesthesia, vol. 103, no. 4, pp. 538-548, 2009.

[42] C. A. Ibarra, S. Wu, K. Murayama et al., "Malignant hyperthermia in Japan: mutation screening of the entire ryanodine receptor type 1 gene coding region by direct sequencing," Anesthesiology, vol. 104, no. 6, pp. 1146-1154, 2006.

[43] H. Grievink and K. M. Stowell, "Allele-specific differences in ryanodine receptor $1 \mathrm{mRNA}$ expression levels may contribute to phenotypic variability in malignant hyperthermia," Orphanet Journal of Rare Diseases, vol. 5, no. 1, article 10, 2010.

[44] R. L. Robinson, D. Carpenter, P. J. Halsall et al., "Epigenetic allele silencing and variable penetrance of malignant hyperthermia susceptibility," British Journal of Anaesthesia, vol. 103, no. 2, pp. 220-225, 2009.

[45] H. Zhou, M. Brockington, H. Jungbluth et al., "Epigenetic allele silencing unveils recessive RYR1 mutations in core myopathies," American Journal of Human Genetics, vol. 79, no. 5, pp. 859-868, 2006.

[46] H. Zhou, H. Jungbluth, C. A. Sewry et al., "Molecular mechanisms and phenotypic variation in RYR1-related congenital myopathies," Brain, vol. 130, no. 8, pp. 2024-2036, 2007.

[47] M. G. Chelu, S. A. Goonasekera, W. J. Durham et al., "Heat- and anesthesia-induced malignant hyperthermia in an RYR1 knockin mouse," FASEB Journal, vol. 20, no. 2, pp. 329-330, 2006.

[48] W. J. Durham, P. Aracena-Parks, C. Long et al., "RYR1 Snitrosylation underlies environmental heat stroke and sudden death in Y522S RYR1 knockin mice," Cell, vol. 133, no. 1, pp. 5365, 2008.

[49] J. T. Lanner, D. K. Georgiou, A. Dagnino-Acosta et al., "AICAR prevents heat induced sudden death in RYR1 mutant mice independent of AMPK activation," Nature Medicine, vol. 18, no. 2, pp. 244-251, 2012.

[50] B. T. Corona, S. L. Hamilton, and C. P. Ingalls, "Effect of prior exercise on thermal sensitivity of malignant hyperthermiasusceptible muscle," Muscle and Nerve, vol. 42, no. 2, pp. 270$272,2010$. 

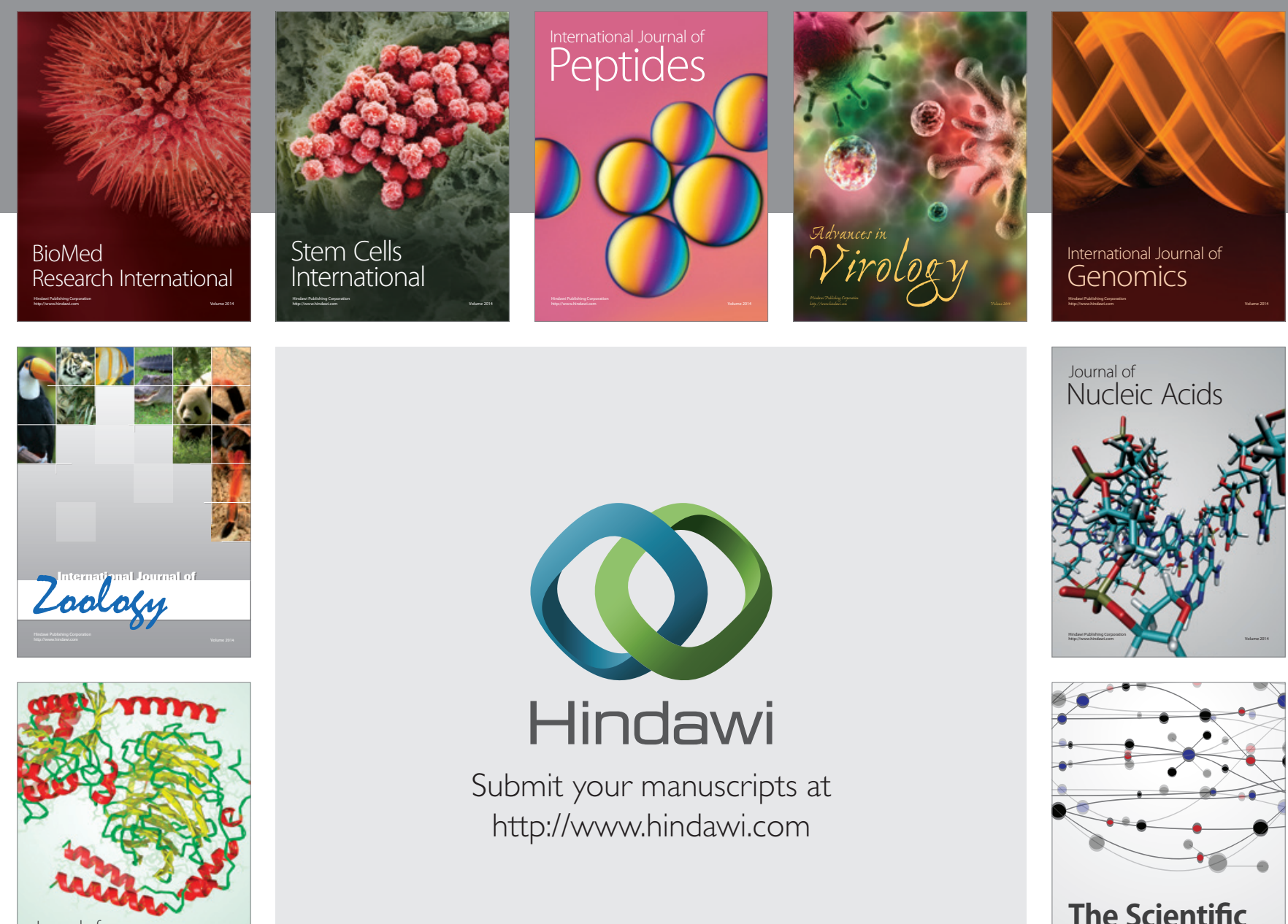

Submit your manuscripts at

http://www.hindawi.com

Journal of
Signal Transduction
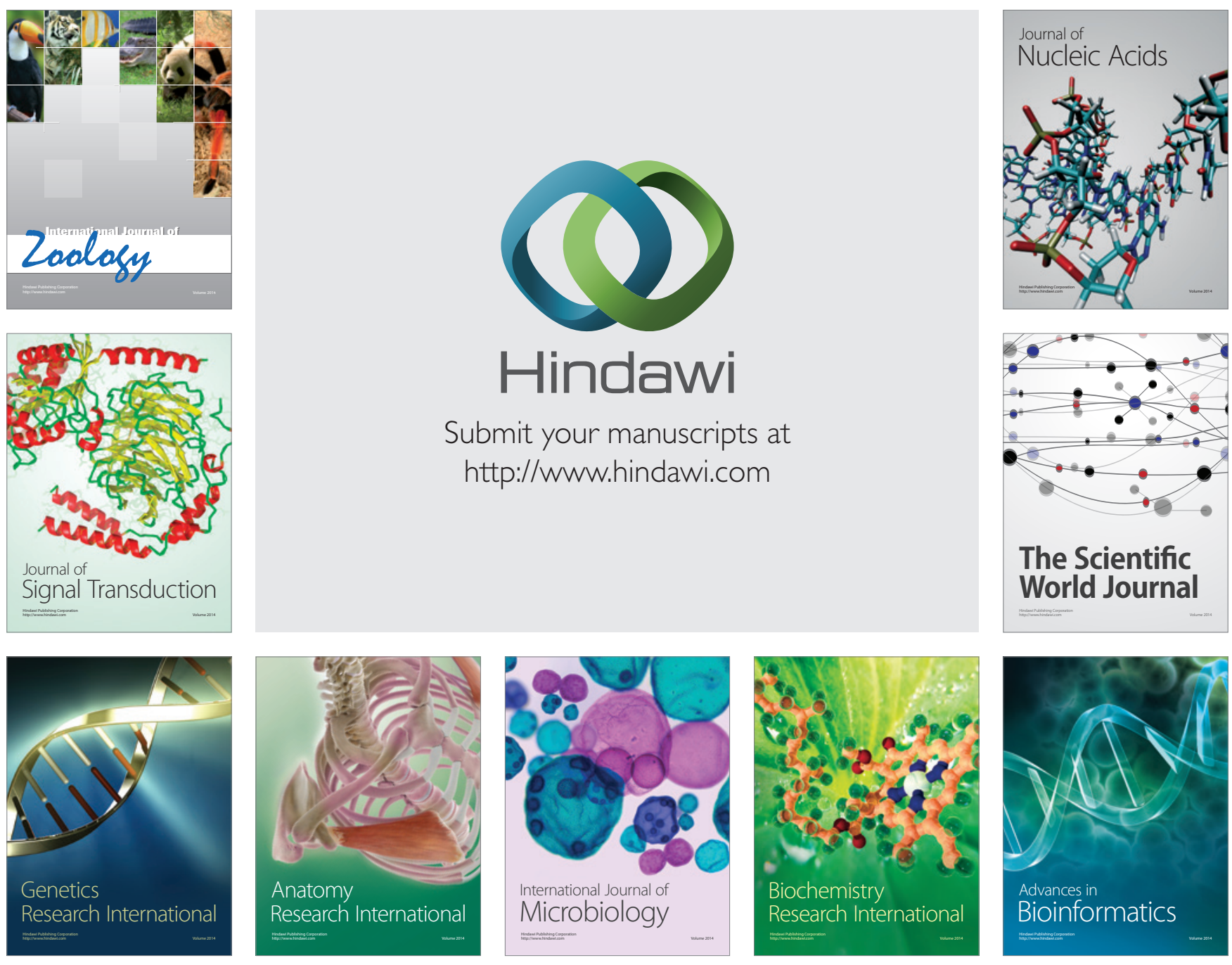

The Scientific World Journal
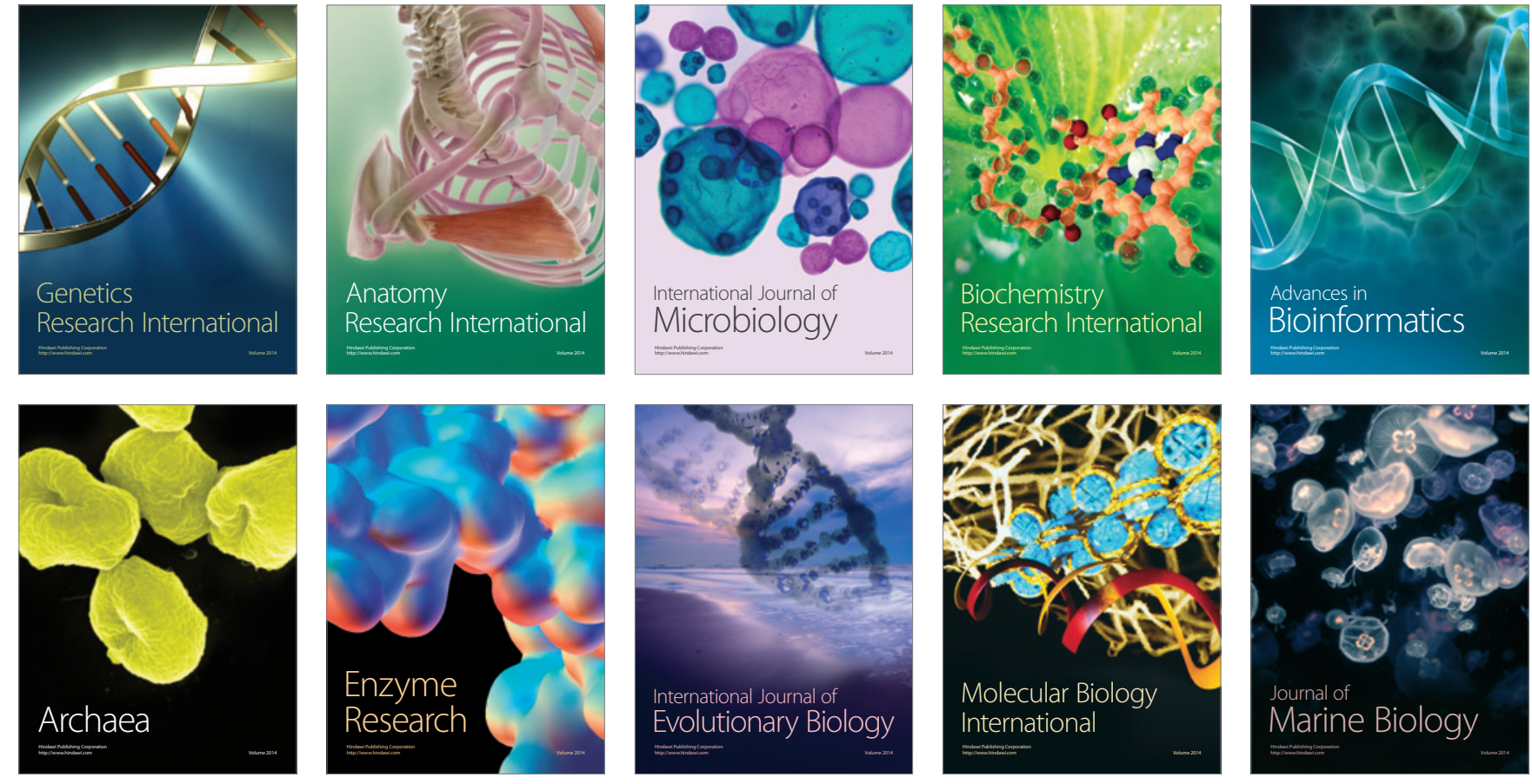